تاثير اشعة كاما في الكالس المستحث وامكانية اخلاف نباتات منه لأربعة تراكيب

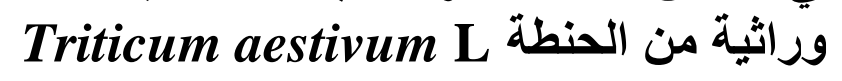

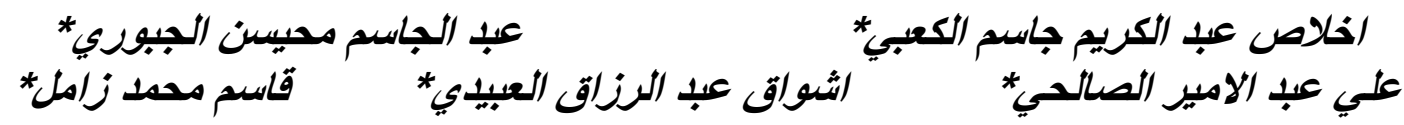

2006/12/3 - تاريخ قبول النشر

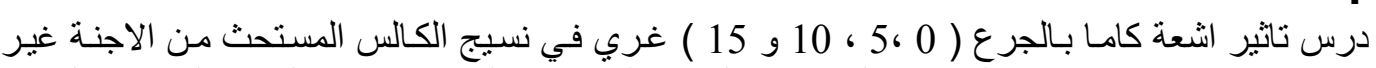

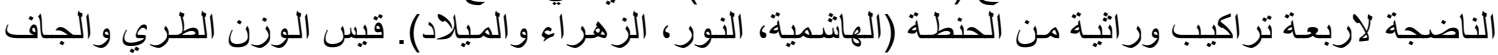

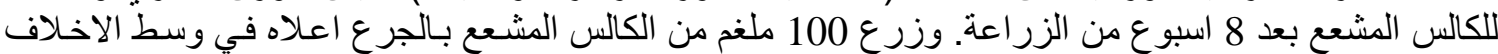

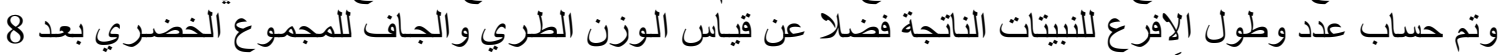

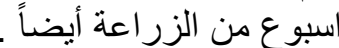

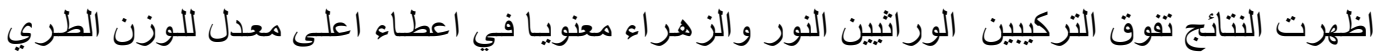

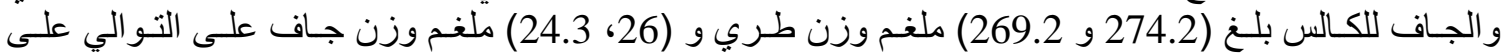

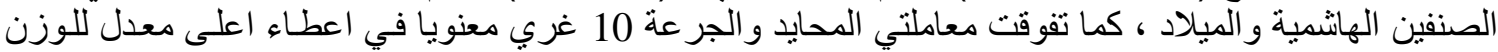

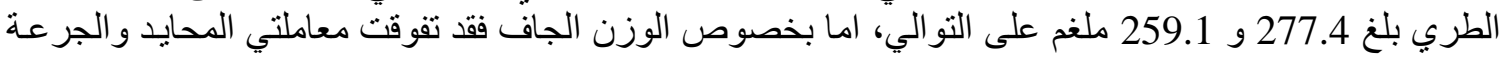

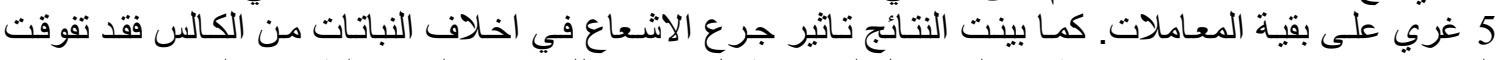

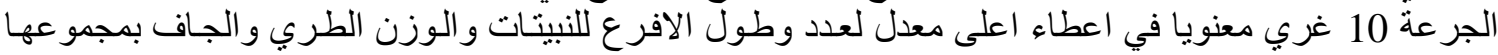

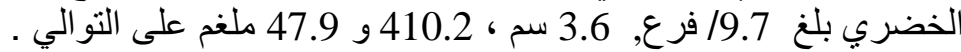

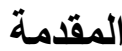

Ahloowalia

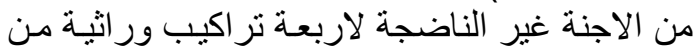

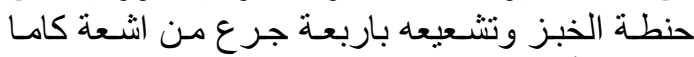

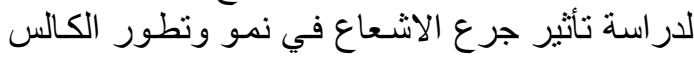
وفي اخلاف النباتات من الكالس المشعع .

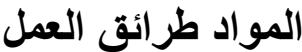 زراعة الاجنة الموان}

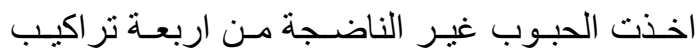

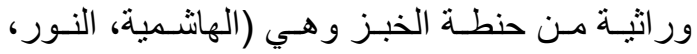

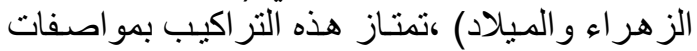

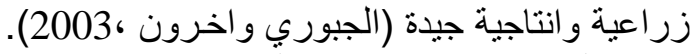

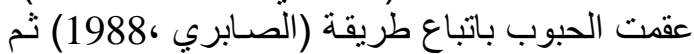

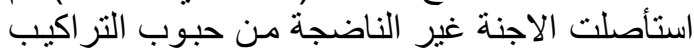

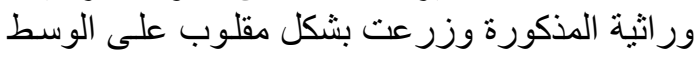
الغذائي Murashigae ) MS و و M Skoog ، 1962 ) و المتكون من الامـلاح اللاعضوية بقوة مضـاعفة مضافاً اليه

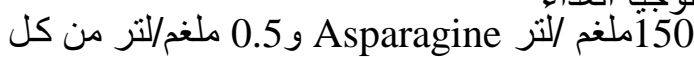
من Kinetin, Thiamine $\mathrm{HCl}$, Pyridoxine 2,4- بالاضـافة الى 2 ملغم/لتر التر D 30 غم/لتر سكروز و 7.5 غم/لتر اجار و المعقم بجهاز التعقيم البخاري بدرجة حرارة 121 مُ مُ وضغط

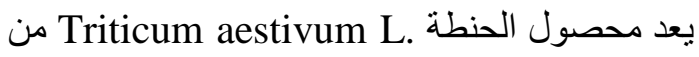

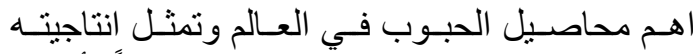

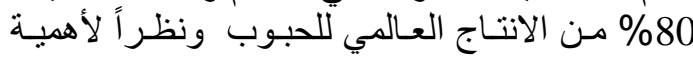

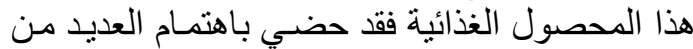

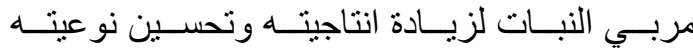
باستخدام طر ائق التربية التقليديـة كالتهجين و الادخـال

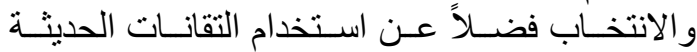

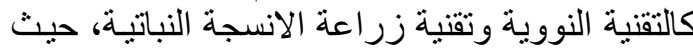

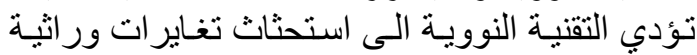

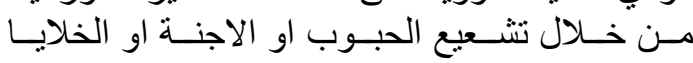

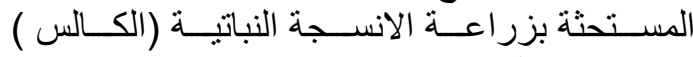

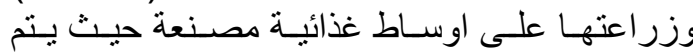

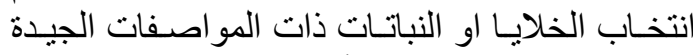

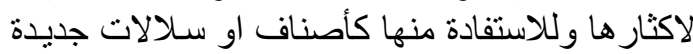

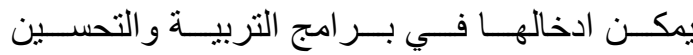
(1979، HellوKerbauy)

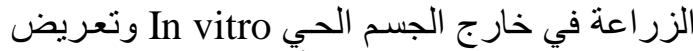

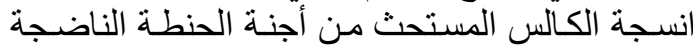
و غير الناضجة للمطفرات الفيزياوية او الكيمياوية قد المدان

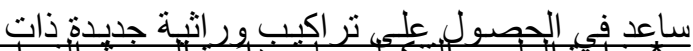

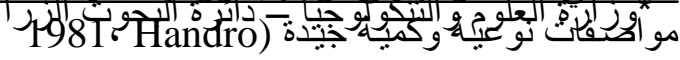
واخرى متحملة لظروف الثد البيئي (الجبوري و واخـرون ، 2001). كمــا اسـتخدمت هذه التقنيـة في

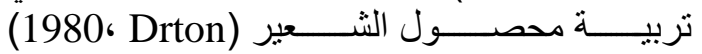
و الرز(خضر واخرون ،2000) و البطاطـا ( , 1990 


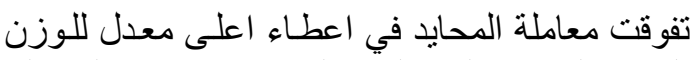

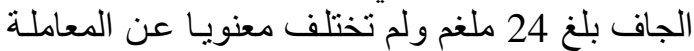
5 غري الا انها اختلفت معنوياعن بقية المعاملات.

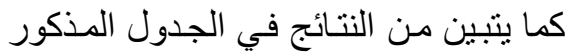
تفوق التركيب الور اثي النور معنويـا على التر اكيب التيب

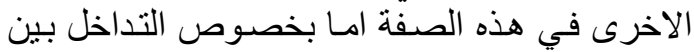

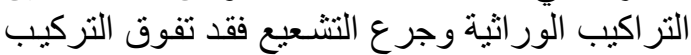

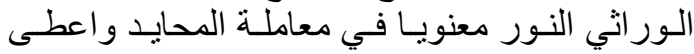

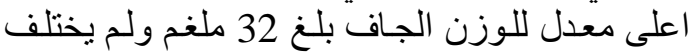

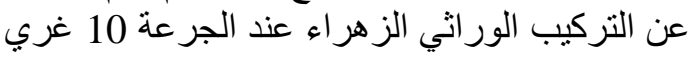
الا انه اختلف عن بقية التداخلات.

جدول (1) تأثير جرع التشعيع في معدل الوزن الطري

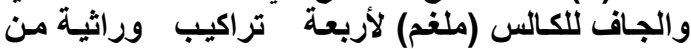

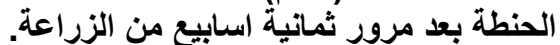

\begin{tabular}{|c|c|c|c|c|c|}
\hline \multicolumn{6}{|c|}{ الوزن الطري (ملغم) } \\
\hline \multicolumn{6}{|c|}{ التراكيب الور اثية } \\
\hline 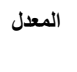 & 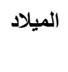 & 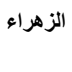 & 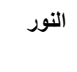 & الهاشمية & (غري) \\
\hline 277.4 & 318.7 & 294.3 & 343.0 & 153.7 & 0 \\
\hline 245.4 & 145.6 & 257.3 & 281.7 & 297.0 & 5 \\
\hline 259.1 & 252.3 & 314.7 & 268 & 201.3 & 10 \\
\hline 212.8 & 233.0 & 210.3 & 204.7 & 203.0 & 15 \\
\hline & 237.4 & 269.2 & 274.4 & 213.8 & المعدل \\
\hline للجرع = & \multicolumn{5}{|c|}{ أ.ف.م (0.05) للتر اكيب الور اثية = 30.05 $30.05 \quad 60.11=ل$ للتداخل } \\
\hline \multicolumn{6}{|c|}{ الوزن الجاف } \\
\hline 24.0 & 28.3 & 25.3 & 32.0 & 10.3 & 0 \\
\hline 23.3 & 14.0 & 22.3 & 28.7 & 28.3 & 5 \\
\hline 22.0 & 20.0 & 29.7 & 22.0 & 16.3 & 10 \\
\hline \multirow[t]{2}{*}{20.2} & 21.3 & 20.0 & 21.3 & 18.3 & 15 \\
\hline & 20.9 & 24.3 & 26.0 & 18.3 & المعدل \\
\hline \multicolumn{3}{|c|}{ 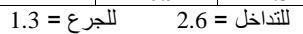 } & $1.3=\frac{1}{1}=4$ & 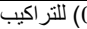 & 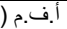 \\
\hline
\end{tabular}

\section{2.تاثير جرع التشعيع في الاخلاف} والتضاعف الخضري

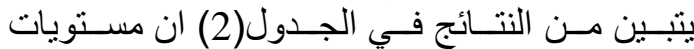

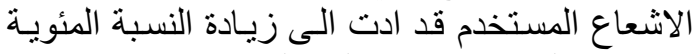

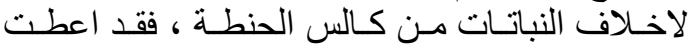

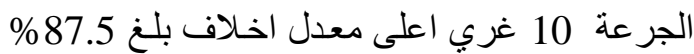

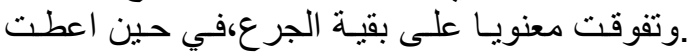

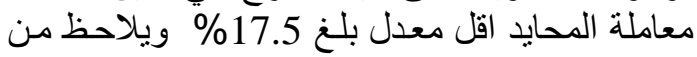

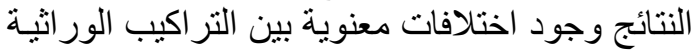
المدروسة فقد تفوق التركيب الور اثي الهاتشمية معنويا لترائ

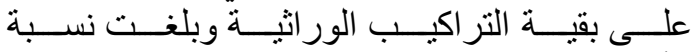
الأخلاف70\%. في حين اعطى التركيبين الور اثيين النور و الزهر اء اقل معدل بلغ 55\% لكل اعل منهما ، كمـا

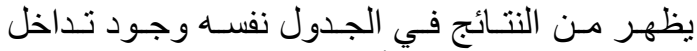
معنوي بين مستويات الأشعاع و التر اكيب الور اثية فقد

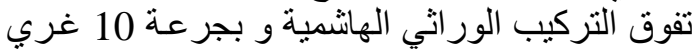

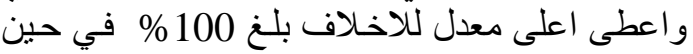
اعطى التركيبين الور اثيين النور والئل المبلاد اقل معدل في معاملة المحايد بلغت 10\% الكر الكر و

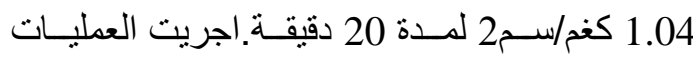

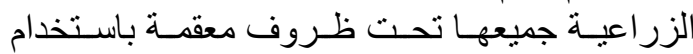

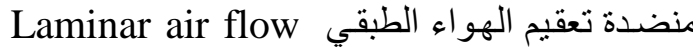

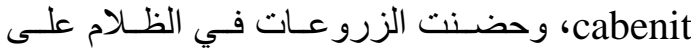

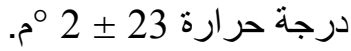

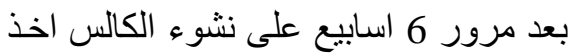
تشعيع الكالس وزن ثابت من كالس كل تركيب ور اثي

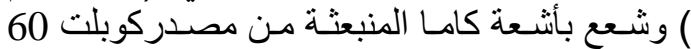

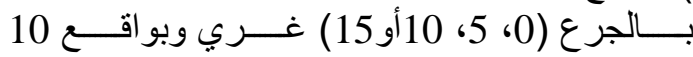

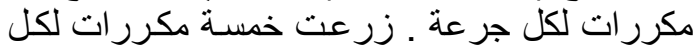
جر عة ولكل تركيب ور اثي على نفر نفس الوسط الغذائي

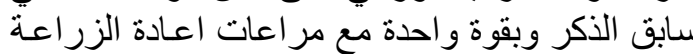

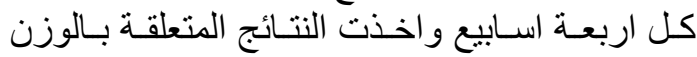

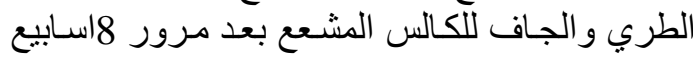

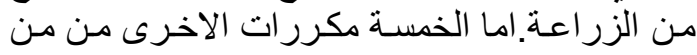

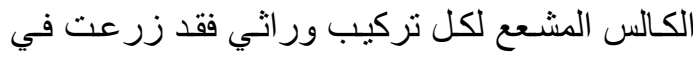

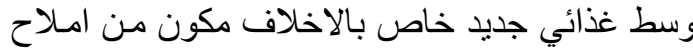

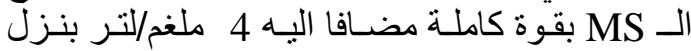
ادنين BA و 0.5 ملغم/لتـر مـن كـل مـن النفتـالين حامض الخليك NAA و اندول حامض الخليك

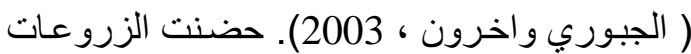

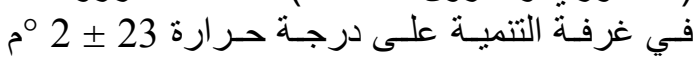

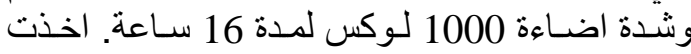

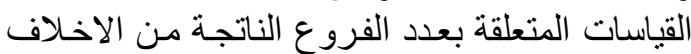

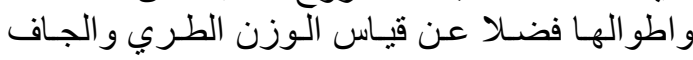
للمجموع الخضري بعد 8 اسابيع من الزر الطئ.

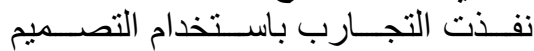

العشو ائي الكامل (C.R.D) وبو اقع خمسـة مكررات

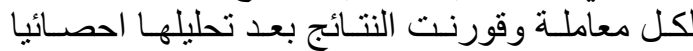

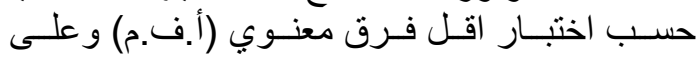

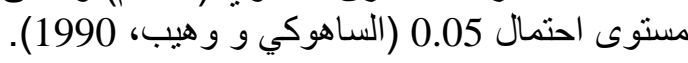

\section{النتائج و المناقشة

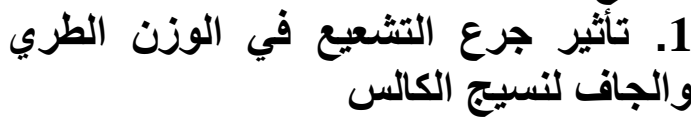
يتبين من النتائج في الجدول (1) ان معاملـة

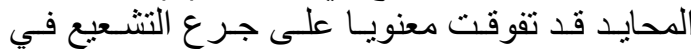

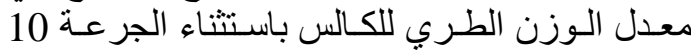

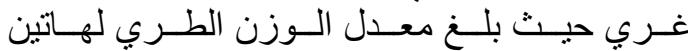

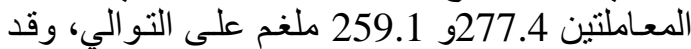

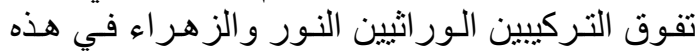

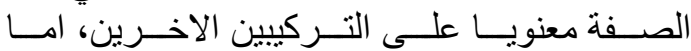

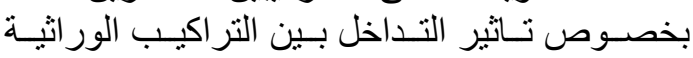

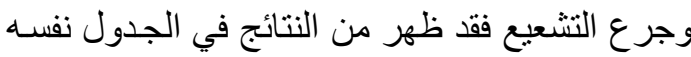

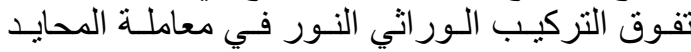

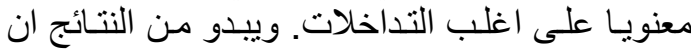

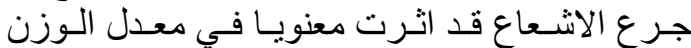
الجاف لكالس التر اكيب الور اثيـة من الحنطـة ، حيث التيث 


\begin{tabular}{|c|c|c|c|c|c|}
\hline 9.7 & 11.0 & 7.3 & 11.0 & 9.3 & 10 \\
\hline \multirow[t]{2}{*}{7.1} & 5.7 & 6.7 & 7.7 & 8.3 & 15 \\
\hline & 6.5 & 5.3 & 6.9 & 6.4 & المعدل \\
\hline \multicolumn{3}{|c|}{ للتداخل = } & 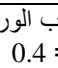 & & أ.ف.م (1.01 \\
\hline \multicolumn{6}{|c|}{ طول الافرع(سم) } \\
\hline 1.9 & 2.0 & 1.8 & 1.7 & 2.2 & 0 \\
\hline 2.9 & 3.4 & 3.2 & 2.3 & 2.8 & 5 \\
\hline 3.6 & 3.2 & 3.4 & 4.1 & 3.8 & 10 \\
\hline \multirow[t]{2}{*}{2.2} & 1.8 & 2.1 & 2.0 & 2.7 & 15 \\
\hline & 2.6 & 2.6 & 2.5 & 2.9 & المعدل \\
\hline \multicolumn{2}{|c|}{ للتنداخل = 0.5} & & ور اثية & للجر & أ.ف.م ) \\
\hline
\end{tabular}

\section{3. تأثير الجرع الأثشعاعية في الوزن الطري

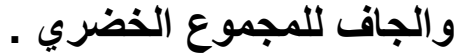

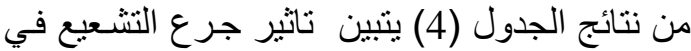

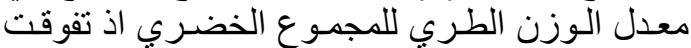

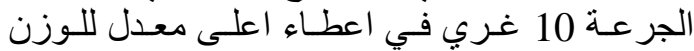

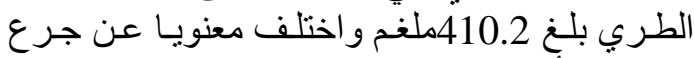

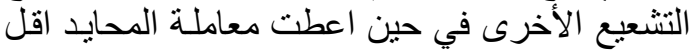

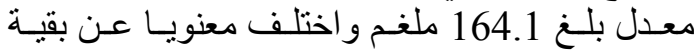

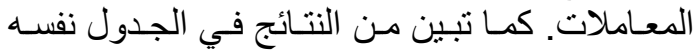

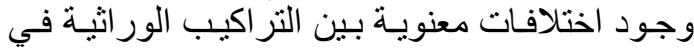
هذه الصفة وتفوق التركيب الور اثي المبلاد معنويـا

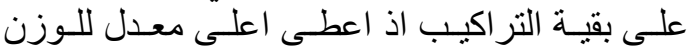

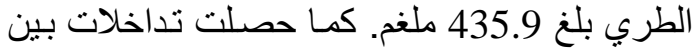

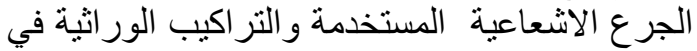

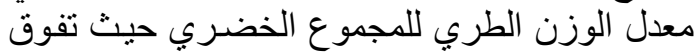

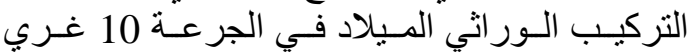
معنويـا على جميع التداخلات واعطى معدل وزن لئل طري بلغ 681 ملغ. الما بخصوص الوزن الجاف للمجموع الخضري فان

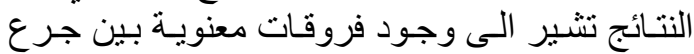

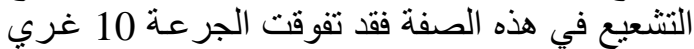

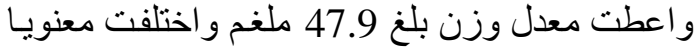

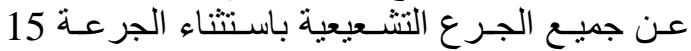

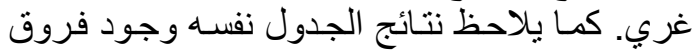

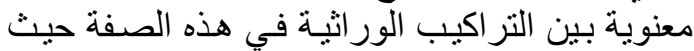

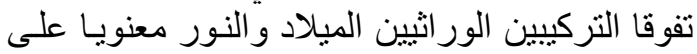

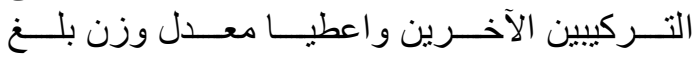

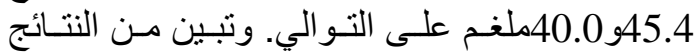
اليضا وجود تداخلات معنوية بين التر اكيب الور اثئية والجرع الثنتعيعية حيث تفوق التركيب الور اثني النور

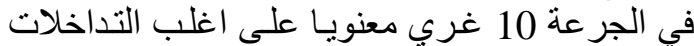

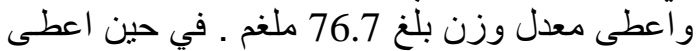

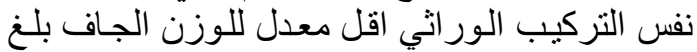

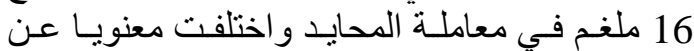

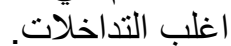

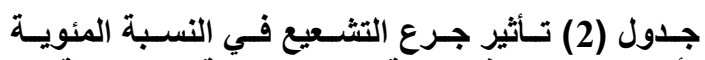
لأخلاف النباتات في اربعة تراكيب وراثيَّة من الحنطة بعد

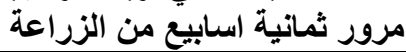

\begin{tabular}{|c|c|c|c|c|c|}
\hline \multicolumn{6}{|c|}{ التراكيب الوراثية } \\
\hline المعدل & الميلاد & الزهراء & النور & الهاشمية & (غري) \\
\hline 17.5 & 10 & 30 & 10 & 20 & 0 \\
\hline 57.5 & 50 & 50 & 60 & 70 & 5 \\
\hline 87.5 & 90 & 80 & 80 & 100 & 10 \\
\hline \multirow[t]{2}{*}{77.5} & 90 & 60 & 70 & 90 & 15 \\
\hline & 60 & 55 & 55 & 70 & المعدل \\
\hline \multicolumn{5}{|c|}{ للتداخل= 2.8} & أ.ف.م (5) ألجرع.5. \\
\hline
\end{tabular}

تنثير النتائج في الجدول(3 ) الى تفوق الجرعة 10

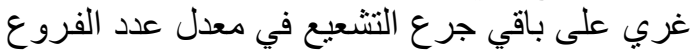

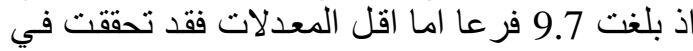

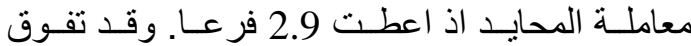

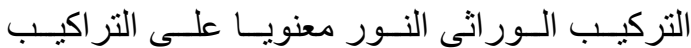
الاخرى بأستثناء التركيب الور اثي الميلاد.

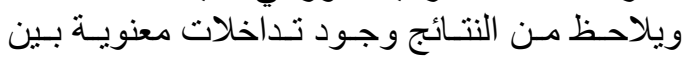
التراكيب الوراثية وجرع الاشتعاع المستخدم في هذه

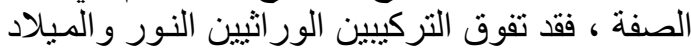

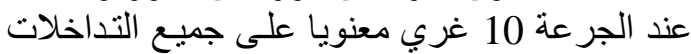

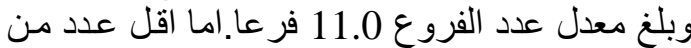
الفروع فقد تحقق في معاملة الدحايد للتركيب الور الثي

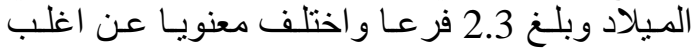
التداخلات.ويظهر من النتائج في الجدول نفسه ايضـا تفوق الجرعة 10 غري في اعطاء اعلى معدل لطول

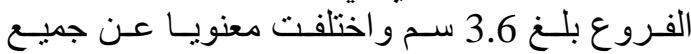
المعاملات، وتفوق التركيب الور اثني الهاثمية على سلى

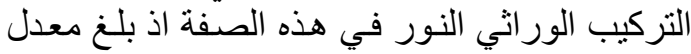

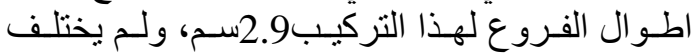
معنويا عن التركيبين الآخرين

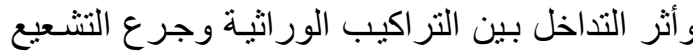
في صفة الطول فقد تفوق التركيب الور راثي النور عند الند

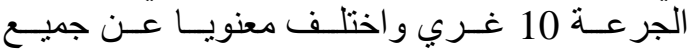

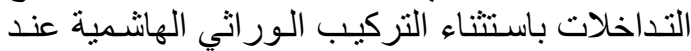

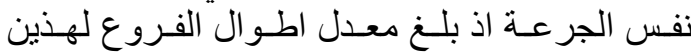

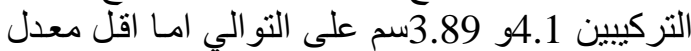
لأطوال الفروع فقد تحقق للتركيب الور اثلي الني النور

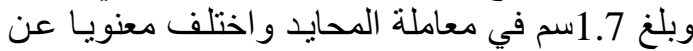

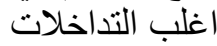

جدول (3) تأثير جرع التشعيع في معدل عداد وطول

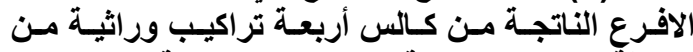
الحنطة بعد مرور ثمانية اسابيع من الززراعة.

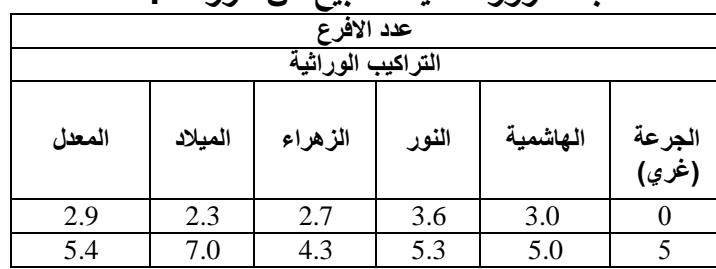


من خلال هذا البحث نوصي باستخدام الجرعة الجـا

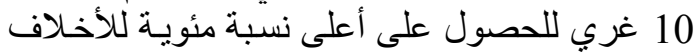

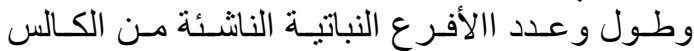

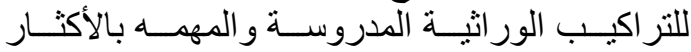
باستخدام تقنية زر اعة الأنسجة النباتية .

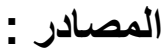

1. الجبوري ، عبد الجاسم محيسن ، عليز علي عبيد

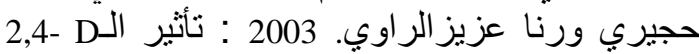

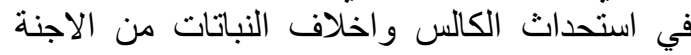
Tritcum الناضجة لاربعة اصناف من حنطة الخبز 3 aestivum L.

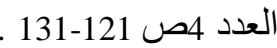

2. الجبوري ، عبد الجاسم محيسن ومحمود اسماعيل سلبي و السوداني ميثم عبد الهادي وسعيد محمد البيد وسهي . 2003 : : تقويم وانتخاب التر اكيب الوراثية

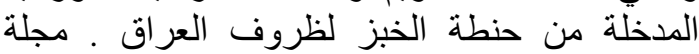
العلوم الزر اعية العر اقية ـ المجلد 34 العدد 1 ص لطر 113

3. الجبوري، عبد الجاسم محيسن ومهدي علي عبد

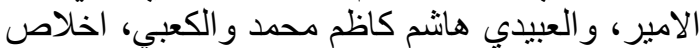

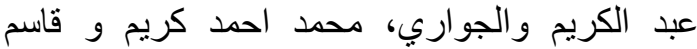

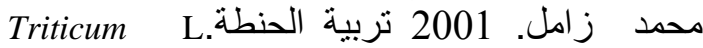

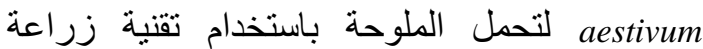
الانسجة واشعة كاما. مجلة ابحاث التقنية الحيوية.

المجلد 3 العدد 2 ص الانعة كانسا.

4. الساهوكي، مدحت ورو هيب كريمة احمد. 1990. تطبيقات في تصميم وتحليل التجارب. ولئ وزارة التعليم

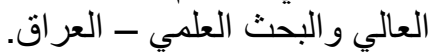

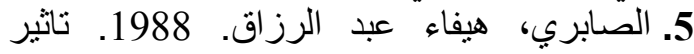

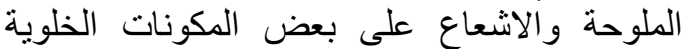

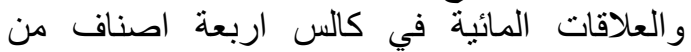

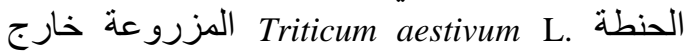
الجسم الحي، رسالة ماجستير، كلية التربية. جامعة

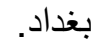

6. الصالحي، علي عبدالإمير مهدي، 2003.

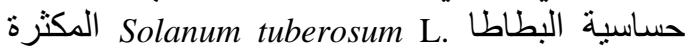
خارج الجسم الحي لاشعة كاما. اطروحة دكنور البطاه ـ كلية الزر اعة- جامعة بغدادهـ البستنة.

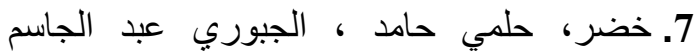
محيسن ور عد هاثنم بكر 2000 استخدام تقنية زر اعة اعنة الانسجة في تحديد تحمل ثثلاثة اصناف من الثناف الرز م اللثد الملحي ـ مجلة ابحاث

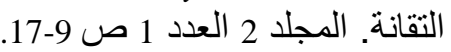

8. Ahloowalia, B.S. 1990. In virto radiation induced mutagenesis in potato. In: The Impact of Biotechnology in Agriculture. Sangwan, R.S. and B.S. Snagwan - Norreel (Eds.) Kluwer Acad. Pub., Dordreacht. PP. 39-46 Ireland.

\begin{tabular}{|c|c|c|c|c|c|}
\hline \multicolumn{6}{|c|}{ 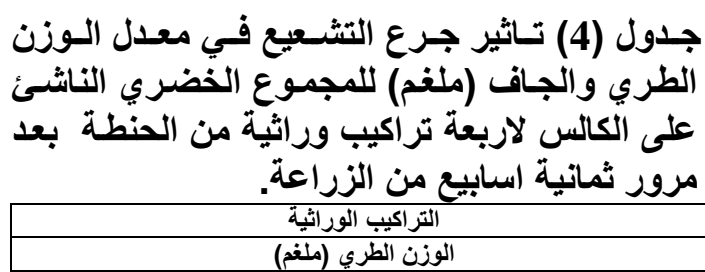 } \\
\hline المعدل & الميلاد & الزهراء & النور & الهاشمية & الجري)ة \\
\hline 164.1 & 188.3 & 128.3 & 208.0 & 131.7 & \\
\hline 254.2 & 401.3 & 159.0 & 290.3 & 166.3 & \\
\hline 410.2 & 681 & 202.7 & 427.7 & 329.3 & 10 \\
\hline \multirow{2}{*}{358.6} & 473 & 273.3 & 392.3 & 295.7 & 15 \\
\hline & 435.9 & 190.8 & 329.6 & 230.8 & المعدل \\
\hline \multicolumn{6}{|c|}{ 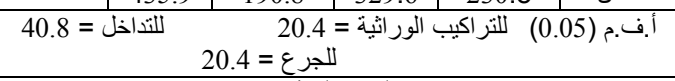 } \\
\hline \\
\hline 17.3 & 17.0 & 18.0 & 16.0 & 18.0 & 0 \\
\hline 29.0 & 43.0 & 20.0 & 32.0 & 21.0 & 5 \\
\hline 47.9 & 68.7 & 20.0 & 76.7 & 26.3 & 10 \\
\hline \multirow{2}{*}{39.8} & 53.0 & 31.7 & 35.5 & 39.3 & 15 \\
\hline & 45.4 & 22.4 & 40.1 & 26.2 & المعدل \\
\hline \multicolumn{6}{|c|}{ لالتداخل } \\
\hline
\end{tabular}

ان التناسب الطردي بين الجرع الأشتعاعية

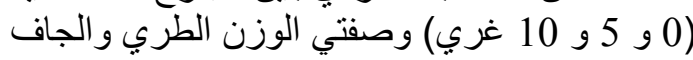

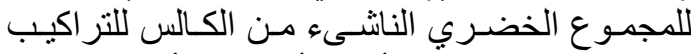

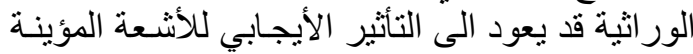

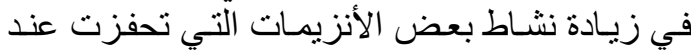

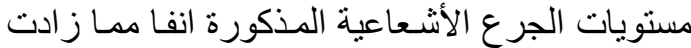

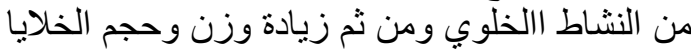

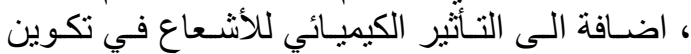

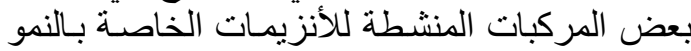

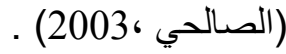

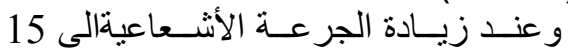

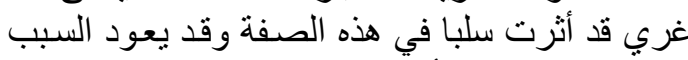

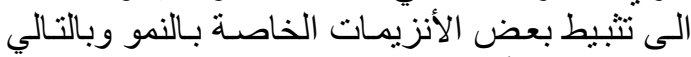

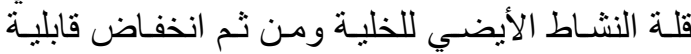
الخلايا على تجميع الاحماض الإئية الاينية اللازمة لعملية

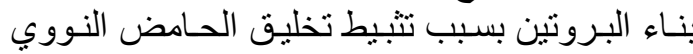

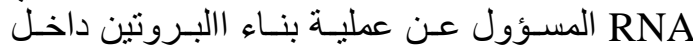

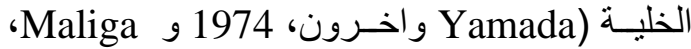

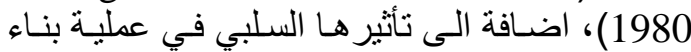

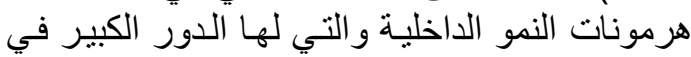

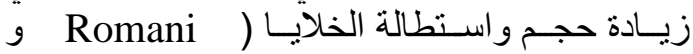
.) (1983 ، Somagyi

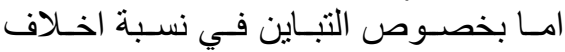

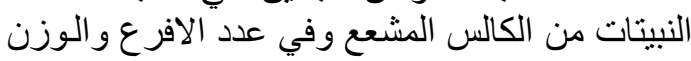

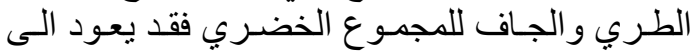

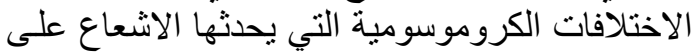

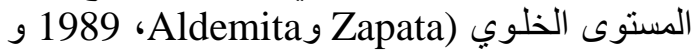

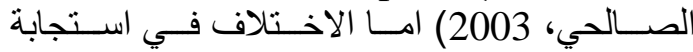

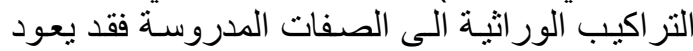

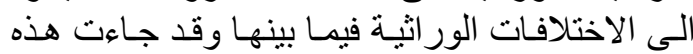

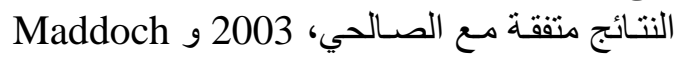
واخرون، 1983 و الجبوري واخرون، 2003 . 
13. Maliga, P. 1980. Resistant mutants and their use in genetic manipulation. Int-Rev. Cyt. Suppl. 11A:381-392.

14. Murashige, T. and. Skoog, F. 1962. A revised medium for rapid growth and bioassys with tobacco tissue culture. Physiol Plant. 15:473-497.

15. Romani , R. J. and L.P.Somogyi .1983.Pectic enzymes, Pectic substances changes by irradiation in plants tissues. Annual Rept. Contract No.AT(111)34,Project Agreement No.80.Univ.of Calif.USA.

16. Yamada, Y., Yasuda, T. \& Yajima, Y. 1974 "In: Plant growth substances" Hirokowa publishing Co., Tokyo, Japan. 17. Zapata, F. and Aldemita, R. 1989. Induction of salt tolerance on high yielding rice varieties through mutagenesis and anther culture, pp. 193202. In Maluszynski, M. (ed.) Advance in Agricultural biotechnology, Kluwer Academic publishers.
9. Drton,T.J.1980. Comparison of salt tolerance between Hordeum vulgare L. and H.Jabatum L. in whole plants and Callus culture . Z pflanzenphsiol . 98: 105-118.

10. Handro, W. 1981. Mutagenesis and in vitro selection. PP. 155-180 In: T. Thorpe (ed.). Plant Tissue Culture Methods and Applications in Agriculture. Academic Press, New York. 11. Kerbauy, G.B. and Hell K.G. 1979. Effect of gamma radiation on the in vitro growth of excised pith cells on Nicotiana tabacum L. cv. IAC-70. Int.J. Radiat. Biol. 35: 273-276.

12. Maddock Se, Lancaster VA, Risiott $\mathrm{R}$ and Franklin J. 1983. Plant regeneration from cultured immature embryos and inflorescences of 25 cultivars of wheat. J. Exptl. Bot. 34:915926.

\title{
Effect of Gamma Radiation on Callus Induction and Plant Regeneration of four Wheats Triticum aestivum L. Genotypes
}

\author{
EKLAS.A.AL Kaaby* \\ A.A.M. AL- jibouri* \\ Ali.A.ALSalhy* \\ Ashwak .A.AL-Aubaidy* \\ Qassim,M, Zamil*
}

*Ministry of Science and Technology . Agricultural Research and Food Technology Directorate . 


\begin{abstract}
The effect of gamma radiation at the doses $(0,5,10$ or 15$)$ Gray on the callus of four Triticum aestivum immature embryos genotypes (AL-Hashmiya , AL-Noor AL-Zahraa and AL-Mellad ) were studied. The fresh and dry weight for callus and shoot tips beside numbers and lengths of the shoots were used as indicators after 8 weeks .

Results revealed that (AL-Noor and AL-Zahraa ) was superior by giving highest fresh and dry weight reached 274.2 and $269.2 \mathrm{mg}$ and 26 and $24.3 \mathrm{mg}$ respectively as compared with AL-Hashmiya and AL-Mellad. Moreover, the control treatment and the dose 10 Gray gave highest fresh weight reached 277.4 and $259.1 \mathrm{mg}$ while the dry weight was highest in the control treatment and the dose 5 Gray. addition 10 Gray dose was superior to give highest rate for the number, length, fresh and dry weight of shoots reached 9.7 shoots , $3.6 \mathrm{~cm}$ length, 410.2 and $47.9 \mathrm{mg}$ on respectively.
\end{abstract}

